\title{
Unravelling the Thermal Decomposition Parameters for The Synthesis of Anisotropic Iron Oxide Nanoparticles
}

\author{
Geoffrey Cotin ${ }^{1,2}$, Céline Kiefer ${ }^{1,2}$, Francis Perton ${ }^{1,2}$, Dris Ihiawakrim ${ }^{1,2}$, \\ Cristina Blanco-Andujar ${ }^{1,2}$, Simona Moldovan ${ }^{1,2}$, Christophe Lefevre ${ }^{1,2}$, Ovidiu Ersen ${ }^{1,2}{ }^{\mathbb{D}}$, \\ Benoit Pichon 1,2, Damien Mertz 1,2 (1) and Sylvie Bégin-Colin 1,2,* \\ 1 Institut de Physique et Chimie des Matériaux de Strasbourg, UMR 7504, University of Strasbourg, CNRS, \\ F-67034 Strasbourg, France; geoffrey.cotin@ipcms.unistra.fr (G.C.); celine.kiefer@ipcms.unistra.fr (C.K.); \\ francis.perton@ipcms.unistra.fr (F.P.); dris.ihiawakrim@ipcms.unistra.fr (D.I.); \\ cristina.blancoandujar.09@ucl.ac.uk (C.B.-A.); simona.moldovan@ipcms.unistra.fr (S.M.); \\ Christophe.lefevre@ipcms.unistra.fr (C.L.); ovidiu.ersen@ipcms.unistra.fr (O.E.); \\ benoit.pichon@ipcms.unistra.fr (B.P.); damien.mertz@ipcms.unistra.fr (D.M.) \\ 2 Labex CSC, Fundation IcFRC/University of Strasbourg, 8 allée Gaspard Monge BP 70028 F, \\ 67083 Strasbourg CEDEX, France \\ * Correspondence: sylvie.begin@ipcms.unistra.fr; Tel.: +33-388-107-192
}

Received: 1 October 2018; Accepted: 22 October 2018; Published: 29 October 2018

\begin{abstract}
Iron oxide nanoparticles are widely used as a contrast agent in magnetic resonance imaging (MRI), and may be used as therapeutic agent for magnetic hyperthermia if they display in particular high magnetic anisotropy. Considering the effect of nanoparticles shape on anisotropy, a reproducible shape control of nanoparticles is a current synthesis challenge. By investigating reaction parameters, such as the iron precursor structure, its water content, but also the amount of the surfactant (sodium oleate) reported to control the shape, iron oxide nanoparticles with different shape and composition were obtained, in particular, iron oxide nanoplates. The effect of the surfactant coming from precursor was taking into account by using in house iron stearates bearing either two or three stearate chains and the negative effect of water on shape was confirmed by considering these precursors after their dehydration. Iron stearates with three chains in presence of a ratio sodium oleate/oleic acid 1:1 led mainly to nanocubes presenting a core-shell $\mathrm{Fe}_{1-\mathrm{x}} \mathrm{O} @ \mathrm{Fe}_{3-\mathrm{x}} \mathrm{O}_{4}$ composition. Nanocubes with straight faces were only obtained with dehydrated precursors. Meanwhile, iron stearates with two chains led preferentially to the formation of nanoplates with a ratio sodium oleate/oleic acid 4:1. The rarely reported flat shape of the plates was confirmed with 3D transmission electronic microscopy (TEM) tomography. The investigation of the synthesis mechanisms confirmed the major role of chelating ligand and of the heating rate to drive the cubic shape of nanoparticles and showed that the nanoplate formation would depend mainly on the nucleation step and possibly on the presence of a given ratio of oleic acid and chelating ligand (oleate and/or stearate).
\end{abstract}

Keywords: iron oxide nanoparticles; synthesis; shape control; thermal decomposition; precursor

\section{Introduction}

In the recent years, synthesis of magnetic nanomaterials and especially nanoparticles (NPs) have been investigated for various applications, due to their unique magnetic properties [1-8]. The shape control of iron oxide nanoparticles (IONPs) is currently considered as promising to enhance the effective anisotropy and/or surface energy of IONPs, which are required for given applications. Indeed, modifying the shape of the NPs will have different impacts. Specific shapes will be enclosed 
by different crystallographic planes that present different surface energies. NPs with specific surface energy is rather important as catalytic applications will look for high energy surfaces $[9,10]$ and they also find applications as biosensors [11]. However, anisotropic shapes interest does not only rely on the NPs surface energy. Modifying the morphology will also have an impact on the magnetic properties by adding shape anisotropy to the NPs effective anisotropy [11-16]. Therefore, IONPs with anisotropic shape have been investigated for biomedical applications and especially for magnetic hyperthermia and magnetic resonance imaging (MRI) applications [17-19].

Among the most interesting shapes of IONPs reported, nanocubes and octopod shaped NPs stand out. Nanocubes of $19 \mathrm{~nm}$ have been shown to be very good heating agents for therapy by magnetic hyperthermia [20]. It has been shown that the cubic morphology boosted the magnetic properties of IONP [20-23]. Furthermore, NPs with faceted shapes exhibited very high contrast enhancement properties promising for imaging by MRI [14,15,24]. Octopod IONPs were demonstrated to be high-performant $T_{2}$ contrast agents for MRI [15].

However, the reproductible control of the NPs shape is not an easy task and remains a challenge. Among current synthesis methods, the thermal decomposition (TD) one is the most developed to tune the size and shape of IONPs. It involves the thermal decomposition of an iron precursor in presence of ligands in an organic solvent $[25,26]$. Commonly, iron precursors, such as acetylacetonates $[23,27,28]$, acetates [23], or oleates [25-27,29], have been decomposed in organic solvents containing surfactants. The strength of this method comes from the possibility to easily separate the NPs nucleation and growth steps following the theory of nucleation-growth proposed by Lamer [30]. This separation is the key parameter as it allows, by playing on synthesis parameters, to tune the size and shape of NPs. Most of the research on the TD synthesis pointed on the major role of the surfactants or ligands on the NPs features. The ligands role is, at first, to coat in situ the NPs preventing aggregation, but it has been demonstrated that ligands can delay (carboxylic acid) or accelerate (amine) the decomposition of the iron precursor [31,32], which will impact the nucleation process. Furthermore, ligands present in the reactant media will direct the growth of the nuclei and may lead towards anisotropic shapes as widely reported [15,18,19,23,24,28,33-38].

Kovalenko et al. [28] reported at first the synthesis of nanocubes by decomposing an iron oleate precursor using a sodium oleate $(\mathrm{NaOl})$ salt along with oleic acid $(\mathrm{OA})$ as ligands. More recently, nanocubes have been synthesized by thermal decomposition by adding dibenzylether (DBE) as solvent in presence of non-chelating ligands, such as oleic acid [21,39]. Guardia et al. [21] demonstrated that the shape control was induced by the product of decomposition of DBE at high temperature. While most of the reports emphasize the role of the ligands, Kim [39] underlined also the role of a kinetically controlled growth under high monomer concentration. Currently, most published results on the synthesis of nanocubes are based on the Kovalenko's method using different combination of ligands (NaOl/OA [22,38,40-42]-OA/Oleylamine [43]—OA/4-Bisphenyl carboxilic acid [39,44]) and iron precursors are mainly iron oleate or iron acetylacetonate. We recently demonstrated that the water content was an important parameter to control the cubic shape as it induces the formation of $\mathrm{NaOl}$ inverse micelles affecting thus the amount of $\mathrm{NaOl}$ available to drive a specific growth [45]. Few papers reported the synthesis of iron oxide nanoplates by the thermal decomposition methods. Zhou et al. [24] succeeded in the synthesis of cubes and plates among other shapes of IONPs by varying the ratio $\mathrm{FeOl} / \mathrm{NaOl}$ and the reaction temperature. Within the many protocols published for the synthesis of anisotropic shapes, every protocol differed from the other involving different heating rates, different ligands, and different concentration, as illustrated in Table 1, and no defined trend came out from the literature. 
Table 1. Some reported nanocubes syntheses from literature.

\begin{tabular}{|c|c|c|c|c|c|c|}
\hline Reference & Precursor & Solvent & Ligand & $\begin{array}{l}\text { Reflux } T \\
\text { and } \\
\text { Duration }\end{array}$ & Heating Rate & Observations \\
\hline \multirow[t]{2}{*}[24]{} & $\mathrm{Fe}(\mathrm{acac})_{3}$ & DBE & OA & $290^{\circ} \mathrm{C} / 30 \mathrm{~s}$ & $20^{\circ} \mathrm{C} / \mathrm{min}$ & $\begin{array}{l}\text { Size and shape control with } \\
\text { time and quantity of DBE }\end{array}$ \\
\hline & $\mathrm{Fe}(\mathrm{acac})_{3}$ & DBE & $\begin{array}{l}\text { OA/4-Bisphenyl } \\
\text { carboxilic acid }\end{array}$ & $290^{\circ} \mathrm{C} / 30 \mathrm{~s}$ & $20^{\circ} \mathrm{C} / \mathrm{min}$ & Smaller cubes \\
\hline [9] & $\mathrm{Fe}(\mathrm{Ol})_{3}$ & OD or TOA & $\mathrm{OA}$ & $340^{\circ} \mathrm{C} / 4 \mathrm{~h}$ & $10-15^{\circ} \mathrm{C} / \mathrm{min}$ & Size controled with $\mathrm{T}$ \\
\hline$[30]$ & $\mathrm{Fe}(\mathrm{acac})_{3}$ & DBE & $\begin{array}{l}\text { OA/4-Bisphenyl } \\
\text { carboxilic acid }\end{array}$ & $290^{\circ} \mathrm{C} / 30 \mathrm{~s}$ & ND & \\
\hline$[25,26]$ & $\mathrm{Fe}(\mathrm{Ol})_{3}$ & Squalane & $\mathrm{NaOl} / \mathrm{OA}$ & $315^{\circ} \mathrm{C} / 2 \mathrm{~h}$ & $20^{\circ} \mathrm{C} / \mathrm{min}$ & Core-shell \\
\hline [29] & $\mathrm{Fe}(\mathrm{acac})_{3}$ & DBE & $\mathrm{OA} / \mathrm{HDD} / \mathrm{OAm}$ & $290^{\circ} \mathrm{C} / 1 \mathrm{~h}$ & $15^{\circ} \mathrm{C} / \mathrm{min}$ & $\begin{array}{l}\text { If heating rate increases along } \\
\text { shorter reflux bigger NPs; on } \\
\text { the opposite smaller NPs }\end{array}$ \\
\hline [7] & $\mathrm{Fe}(\mathrm{Ol})_{3}$ & eicosane & $\mathrm{NaOl} / \mathrm{OA}$ & $350^{\circ} \mathrm{C} / 30 \mathrm{~s}$ & $3.3^{\circ} \mathrm{C} / \mathrm{min}$ & Core-shell \\
\hline [46] & $\begin{array}{l}\mathrm{Fe}(\mathrm{Ol})_{3} \text { in } \\
\text { situ }\end{array}$ & OD & $\mathrm{NaOl}$ & $315^{\circ} \mathrm{C} / 2 \mathrm{~h}$ & ND & $\begin{array}{l}\text { Shape control through } \\
\text { amount of } \mathrm{NaOl}\end{array}$ \\
\hline [47] & $\mathrm{Fe}(\mathrm{Ol})$ ? & OD & $\mathrm{OA}$ & $320^{\circ} \mathrm{C} / 30 \mathrm{~s}$ & $5.5^{\circ} \mathrm{C} / \mathrm{min}$ & \\
\hline [12] & $\mathrm{Fe}(\mathrm{Ol})_{3}$ & OD & $\begin{array}{l}\mathrm{NaOl} / \mathrm{OA} \text { or } \\
\text { DBAOL }\end{array}$ & $315^{\circ} \mathrm{C} / 30^{\prime}$ & $3.3 \% \mathrm{~min}$ & \\
\hline [27] & $\mathrm{Fe}(\mathrm{Ol})_{3}$ & OD & $\mathrm{NaOl} / \mathrm{OA}$ & $315^{\circ} \mathrm{C} / 30 \mathrm{~s}$ & $4^{\circ} \mathrm{C} / \mathrm{min}$ & $\begin{array}{c}\text { Ratio } \mathrm{Fe}(\mathrm{Ol}) / \mathrm{NaOl} \text { control } \\
\text { the size }\end{array}$ \\
\hline [28] & $\mathrm{Fe}(\mathrm{St})_{2}$ & $\mathrm{OA}$ & $\mathrm{NaOl} / \mathrm{OA}$ & $380^{\circ} \mathrm{C} / 2 \mathrm{~h}$ & $5^{\circ} \mathrm{C} / \mathrm{min}$ & \\
\hline [23] & $\mathrm{Fe}(\mathrm{acac})_{3}$ & Squalane & Decanoic acid/DBE & $310^{\circ} \mathrm{C} / 1 \mathrm{~h}$ & $7^{\circ} \mathrm{C} / \mathrm{min}$ & $\begin{array}{l}\text { Size controled with ratio } \\
\text { squalane/DBE }\end{array}$ \\
\hline
\end{tabular}

DBE: Dibenzylether; OA: Oleic acid; TOA: Trioctylamine; HDD: Hexadecylamine; OAm: Oleyamine; OD:

Octadecene; DBAOL: Dibutyammonium oleate; ND: Non Disclosed.

Yet, the ligands used in the synthesis and the heating rates appeared to be the main parameters for the shape control. However, the synthesis mechanism of anisotropic shape is not yet clearly understood.

In our group, core-shell $\mathrm{Fe}_{1-\mathrm{x}} \mathrm{O} @ \mathrm{Fe}_{3-\mathrm{x}} \mathrm{O}_{4}$ nanocubes $[48,49]$ were previously synthesized by adapting the Kovalenko's method [28] (sodium oleate and oleic acid ratio 3.6:1) using an in house iron oleate precursor. Nevertheless, the shape quality of nanocubes was highly dependent on the iron oleate batch and several iron oleate batches were often synthesized without succeeding in obtaining homogeneous nanocubes [45]. Replacing iron oleate by a commercial iron stearate led to shape heterogeneity. By synthesizing in house iron stearates bearing either two $\left(\mathrm{FeSt}_{2}\right)$ or three $\left(\mathrm{FeSt}_{3}\right)$ stearate chains and either hydrated or dehydrated, we showed that the hydration rate of iron stearates was decisive [45]. Nanocubes with straight faces presenting a core-shell composition $\mathrm{Fe}_{1-\mathrm{x}} \mathrm{O}_{\mathrm{O}} \mathrm{Fe}_{3-\mathrm{x}} \mathrm{O}_{4}$ were only obtained with dehydrated $\mathrm{FeSt}_{3}$. Dehydrated $\mathrm{FeSt}_{2}$ led to rounded cubes showing an effect of the nature of the precursor that was explained by different thermal stability of stearates, which influence the kinetics of the monomer generation thus the nucleation.

One may notice that very few papers dealt with the influence of the iron precursor structure on the formation of anisotropic shape by the thermal decomposition method. The pioneer work of Bronstein et al. $[29,50]$ pointed at the role of the precursor structure, which would be affected by washing solvents and that was supported by Buck et al. who reported on the role of the precursor during the study of cobalt oleate $\left(\mathrm{CoOl}_{2}\right)$ [51].

Considering that the synthesis of anisotropic shaped NPs is very important, due to their enhanced properties, the understanding of their synthesis mechanisms is still challenging. In that context and based on our previous investigations $[45,48]$, we propose to investigate the effect of the structure of the precursor, which has been poorly studied up to now, and of the amount of sodium oleate on the nanoparticle shape. That's why in this work, four precursors, hydrated and dehydrated $\mathrm{FeSt}_{2}$ and $\mathrm{FeSt}_{3}$, have been decomposed in anisotropic conditions from an adapted Kovalenko's method [48]. Some important parameters have been thus investigated to better understand the mechanism addressing the shape of NPs: The influence of the structure (and hydration degree) of iron 
stearate, the ratio sodium oleate/oleic acid ( $\mathrm{NaOl} / \mathrm{OA})$ and the heating rate. Then, NPs with cubic, octopod and nanoplate shapes have been structurally characterized.

\section{Experimental Details}

\subsection{Synthesis Methods}

Synthesis of iron stearate precursors. Iron stearate (II) and (III) were prepared by precipitation of sodium stearate (98.8\% TCI, TCI Europe N.V., Zwijndrecht, Belgium), and ferrous chloride (99\%, Acros Organic, Thermo Fischer Scientific, Geel, Belgium) or ferric chloride (99\%, Sigma, Sigma Aldrich, Lyon, France) salts in an aqueous solution as previously reported [46]. Briefly, sodium stearate (9.8 g, $32 \mathrm{mmol}$ ) was transferred into a two necked round bottomed flask (RBF) and solubilized in distilled $\mathrm{H}_{2} \mathrm{O}\left(\mathrm{H}_{2} \mathrm{O}, 80 \mathrm{~mL}\right)$. The solution is heated to reflux and stirred for $30 \mathrm{~min}$ until complete dissolution of the stearate. Separately, $\mathrm{FeCl}_{2} \cdot 4 \mathrm{H}_{2} \mathrm{O}(3.16 \mathrm{~g}, 16 \mathrm{mmol})$ or $\mathrm{FeCl}_{3} \cdot 6 \mathrm{H}_{2} \mathrm{O}(2.88 \mathrm{~g}, 10.6 \mathrm{mmol})$ was dissolved in $\mathrm{H}_{2} \mathrm{O}(40 \mathrm{~mL})$ and added onto the sodium stearate solution under vigorous stirring. A light orange precipitate is formed immediately. The solution is kept under stirring at this temperature for $15 \mathrm{~min}$. Thereafter the solution is allowed to cool down to room temperature (RT). The obtained precipitate is washed once by centrifugation (hot $\mathrm{H}_{2} \mathrm{O}, 14,000 \mathrm{rpm}, 10 \mathrm{~min}$ ). The product is then filtrated with a büchner funnel and oven dried at $65^{\circ} \mathrm{C}$ for $24 \mathrm{~h}$. Dehydration of the precursor is performed in an oven at $140{ }^{\circ} \mathrm{C}$ for $48 \mathrm{~h}$.

NPs Synthesis is adapted from the work of Pichon et al. [48]. $2.32 \mathrm{mmol}$ of iron stearate is mixed with $3 \mathrm{mmol}$ of ligands (oleic acid (OA, 99\%, Alfa Aesar, Thermo Fisher GmbH, Karlsruhe, Germany) and sodium oleate ( $\mathrm{NaOl}, 97 \%, \mathrm{TCI})$ at different ratios) in $15 \mathrm{~mL}$ octadecene (OD, 90\%, Alfa Aesar). The mixture is stirred and heated at $120{ }^{\circ} \mathrm{C}$ for $60 \mathrm{~min}$ without reflux condenser in order to dissolve the reactants and remove the water residues. The cooler is then connected to the flask and the solution is heated up to $200{ }^{\circ} \mathrm{C}$ for $10 \mathrm{~min}$ with a heating rate of $5^{\circ} \mathrm{C} / \mathrm{min}$. The solution is then heated up to $315{ }^{\circ} \mathrm{C}$ with a heating rate of $1{ }^{\circ} \mathrm{C} / \mathrm{min}$ and refluxed for $60 \mathrm{~min}$ under air. After cooling to RT, a black and viscous suspension is obtained that is solubilized in $10 \mathrm{~mL}$ of chloroform. The NPs are then precipitated by the addition of an excess of acetone the first time and washed three times with chloroform and acetone at a ratio of 1:4 at 14,000 rpm for $5 \mathrm{~min}$ by centrifugation. The NPs can finally be suspended in $50 \mathrm{~mL}$ of tetrahydrofurane (THF).

Synthesis of optimized cubes id adapted from [45,48]. Iron oxide nanocubes (NC) were synthesized from iron stearate (III). Iron (III) stearate $(2.72 \mathrm{~g}, 3 \mathrm{mmol})$ was mixed with OA $(0.45 \mathrm{~g}$, $1.5 \mathrm{mmol}$ ) and $\mathrm{NaOl}(0.45 \mathrm{~g}, 1.5 \mathrm{mmol})$ in $15 \mathrm{ml}$ 1-eicosene (EC, 80\%, Sigma Aldrich, Lyon, France) in a two neck- RBF. The mixture is heated to $120^{\circ} \mathrm{C}$ under stirring and kept at this temperature for $30 \mathrm{~min}$ without reflux condenser in order to dissolve the reactants and remove the water residues. The condenser was then connected to the flask and the solution heated to boiling temperature $\left(\approx 343{ }^{\circ} \mathrm{C}, 15^{\circ} \mathrm{C} / \mathrm{min}\right)$. The solution was kept at reflux for $90 \mathrm{~min}$ under air. After cooling to RT, a black gel was obtained. The NPs were washed as previously described.

Synthesis of octopods Iron oxide Nano-octopods (NO) were synthesized from commercial iron stearate (III) $(>60 \%$, TCI). Iron (III) stearate $(0.735 \mathrm{~g}, 0.9 \mathrm{mmol})$ was mixed with OA $(1.02 \mathrm{~g}, 3.6 \mathrm{mmol})$ in $20 \mathrm{~mL}$ dibenzylether (DBE, 99\%, Acros Organic) in a two neck-RBF. The mixture is heated at $120{ }^{\circ} \mathrm{C}$ under stirring and kept at this temperature for $60 \mathrm{~min}$ without reflux condenser in order to dissolve the reactants and remove the water residues. The condenser was then connected to the flask and the solution heated to $250^{\circ} \mathrm{C}\left(5^{\circ} \mathrm{C} / \mathrm{min}\right)$ and kept at this temperature for $60 \mathrm{~min}$. The solution was then brought to $320^{\circ} \mathrm{C}\left(10^{\circ} \mathrm{C} / \mathrm{min}\right)$ and kept at reflux temperature for $60 \mathrm{~min}$ under air. After cooling to $\mathrm{RT}$, a black solution was obtained. The NPs were washed as previously described.

\subsection{Characterization Methods}

NPs were characterized by transmission electron microscopy (TEM, JEOL, Tokyo, Japan) with a JEOL 2100 microscope operating at $200 \mathrm{kV}$ (point resolution $0.18 \mathrm{~nm}$ ). 
The mean size of NPs and their size distribution were calculated from the size measurements of more than 300 nanoparticles using ImageJ software (NIH, Bethesda, MD, USA). The error presented correspond to the standard deviation of the mean diameter determined from all these size measurements.

The X-ray diffraction (XRD, Bruker, Billerica, MA, USA) pattern was recorded at room temperature with a Bruker D8 Advance diffractometer equipped with a monochromatic copper radiation source $(\mathrm{K} \alpha=0.154056 \mathrm{~nm})$ and a Lynx-Eye detector in the $27-65^{\circ}(2 \theta)$ range with a scan step of $0.03^{\circ}$. High purity silicon powder $(\mathrm{a}=0.543082 \mathrm{~nm})$ was systematically used as an internal standard. Profile matching refinements were performed through the Fullprof program [52] using Le Bail's method [53] with the modified Thompson-Cox-Hasting pseudo-Voigt profile function.

Standard Infrared spectra were recorded between 4000 and $400 \mathrm{~cm}^{-1}$ with a Fourier transform infrared (FTIR) spectrometer, Spectrum 100 from Perkin Elmer (Perkin Elmer, Waltham, MA, USA). Samples were gently ground and diluted in non-absorbent $\mathrm{KBr}$ matrixes.

\section{Results and Discussion}

\subsection{Influence of the Structure of Precursors and Sodium Oleate Ligand}

$\mathrm{FeSt}_{2}$ and $\mathrm{FeSt}_{3}$ have been synthesized by a coprecipitation method using $\mathrm{FeCl}_{2} \cdot 4 \mathrm{H}_{2} \mathrm{O}$ and $\mathrm{FeCl}_{3} \cdot 6 \mathrm{H}_{2} \mathrm{O}$ respectively and these stearates have been heat-treated at $140{ }^{\circ} \mathrm{C}$ for $48 \mathrm{~h}$ to remove most of the crystallized water molecules leading to partially dehydrated stearates (named here FeSt ${ }_{3, \mathrm{~d}}$ and $\mathrm{FeSt}_{2, \mathrm{~d}}$ ) [45]. All stearates are composed of $\mathrm{Fe}^{3+}$, due to the oxidative synthesis condition (except FeSt 2 that present a minor $\mathrm{Fe}^{2+}$ contribution), but their structure differed due to the different amount of stearate ligand and different Fe III-carboxylate coordinations (a mixture of bridging and chelating coordinations). No sodium or chloride from reactants are detected in the final product meaning that water molecules stabilize the $\mathrm{Fe}^{3+}$ (or $\mathrm{Fe}^{2+}$ ) center along the carboxylates (to be published results). We showed that the thermal stability of the different iron stearates is highly dependent on their structure, as well as on their hydration degree [45].

Spherical and cubic iron oxide NPs have been then synthesized by thermal decomposition of these precursors in presence of a given alount of surfactants in a high boiling solvent. These precursors have been decomposed using two standard protocols: One for the synthesis of $10 \mathrm{~nm}$ sized spherical nanoparticles (with oleic acid as surfactant and in dioctyl ether $\left(B_{p}=290{ }^{\circ} \mathrm{C}\right.$ )) and the other one for the synthesis of nanocubes (with a mixture of oleic acid and sodium oleate as surfactant and in octadecene $\left.\left(B_{p}=315^{\circ} \mathrm{C}\right)\right)$ [45]. The size of both shaped NPs was found to be dependent on the water content, as well as the cubic morphology [45]. We suggested that the presence of water makes that oleates, used to drive the cubic shape, form micelles instead of stabilizing specific faces of nuclei. That would explain that the cubic morphology is observed only when the water content is low. The nanosphere and nanocube sizes were related to the iron stearate decomposition kinetics: FeSt ${ }_{2}$ and FeSt ${ }_{2, \mathrm{~d}}$ decomposed in larger amount at lower temperature than $\mathrm{FeSt}_{3}$ and thus favor the nucleation instead of the growth step, leading finally to smaller sized NPs [45].

Considering the important role of water content, which would affect the amount of sodium oleate available to drive a cubic growth and a possible effect of the structure of iron stearate, the hydrated and dehydrated stearates have been here decomposed according to a previously published nanocube synthesis protocol [48], adapted from the Kovalenko method [28], and different ratios of $\mathrm{NaOl}$ and OA (keeping the same total molar amount of ligands, only the ratio is varied) were tested. The synthesis involved a quick heating $\left(5^{\circ} \mathrm{C} / \mathrm{min}\right)$ to a step at $200{ }^{\circ} \mathrm{C}$ for $10 \mathrm{~min}$, which is applied to favor the nucleation of NPs (improving the homogeneity of the mean size [31]) and then the reactant mixture is heated up to $315^{\circ} \mathrm{C}$ with a heating rate of $1^{\circ} \mathrm{C} / \mathrm{min}$ and refluxed for $60 \mathrm{~min}$ under air. The same batch of iron precursors was used for the five tested ratios. Figure 1 showed TEM images of NPs obtained by tuning the type of iron stearates and the amount of $\mathrm{NaOl}$. The mean size is determined 
from measurements of 300 NPs and is given with the standard deviation in Table 2, as well as the observed shape. Size distribution graphs are given in Figure S1.

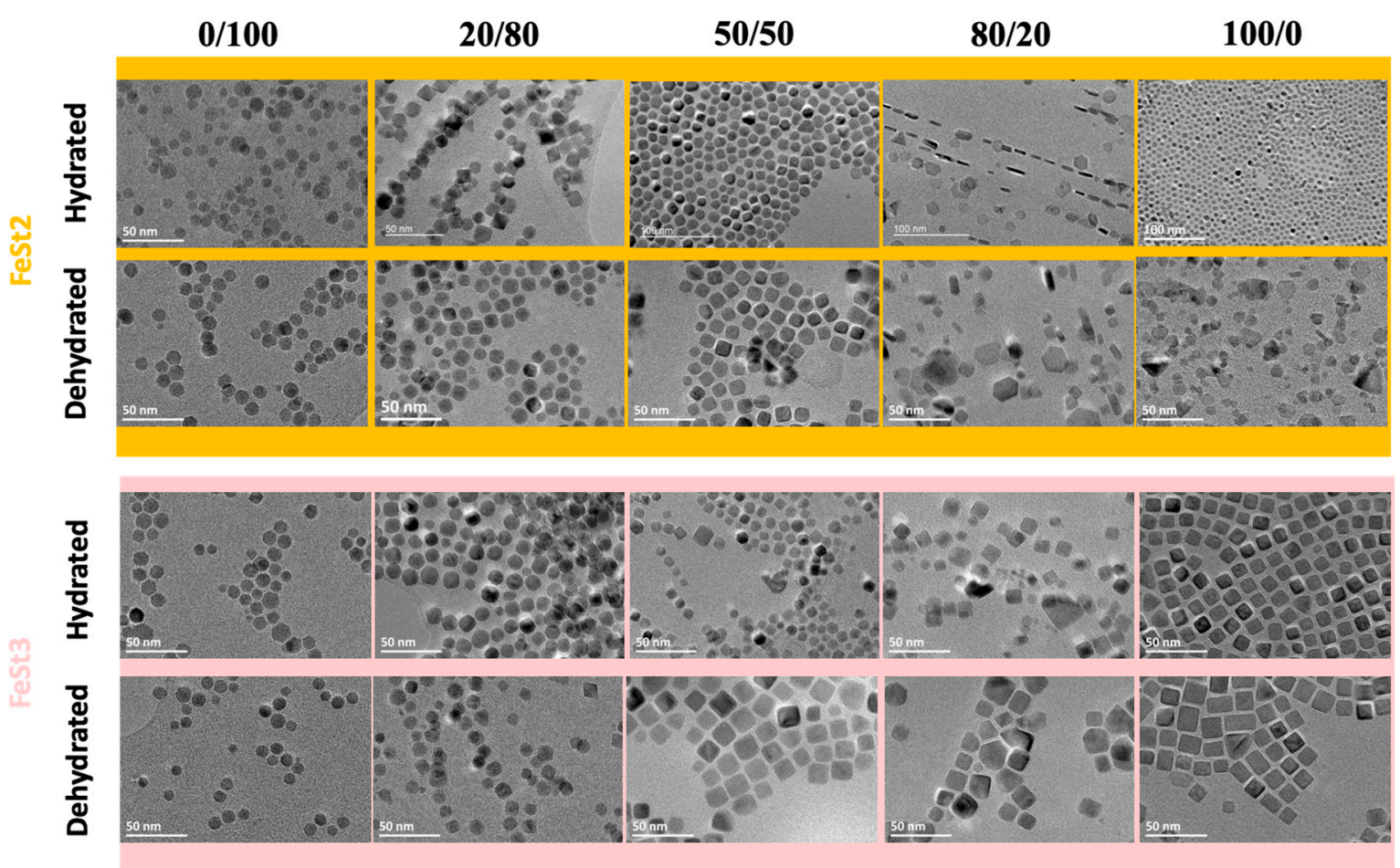

Figure 1. Influence of the ratio $\mathrm{NaOl} / \mathrm{OA}$ on the shape of the nanoparticles (NPs) depending on the precursor structure and hydration degree.

Table 2. Size and shape of nanoparticles as a function of the nature and amount of reactants (M: Majority, m: minatory, r: rare).

\begin{tabular}{|c|c|c|c|c|c|c|}
\hline & rsor & $0 / 100$ & $20 / 80$ & $50 / 50$ & $80 / 20$ & $100 / 0$ \\
\hline \multirow{2}{*}{$\mathrm{FeSt}_{2}$} & Size $(\mathrm{nm})$ & $9.4 \pm 1.9$ & $11.7 \pm 2.5$ & $13.5 \pm 2.5$ & $\begin{array}{c}17.5 \pm 4.4(\mathrm{~L}) \\
6.3 \pm 1.3(\mathrm{t})\end{array}$ & $7.2 \pm 2.4$ \\
\hline & Shape & Spheres & Quasi octahedron & $\begin{array}{l}\text { Deformed } \\
\text { Cubes }\end{array}$ & Plates & Faceted \\
\hline \multirow{2}{*}{$\mathrm{FeSt}_{2, \mathrm{~d}}$} & Size $(\mathrm{nm})$ & $10.0 \pm 1.5$ & $10.9 \pm 1.4$ & $10 \pm 0.6$ & $\begin{array}{l}13.5 \pm 5.2(\mathrm{~L}) \\
66.5 \pm 1.7(\mathrm{t})\end{array}$ & $9 \pm 2.7$ \\
\hline & Shape & Spheres & Quasi spherical & Cubes & Plates & Various faceted plates \\
\hline \multirow{2}{*}{$\mathrm{FeSt}_{3}$} & Size $(\mathrm{nm})$ & $10.8 \pm 1.7$ & $12.4 \pm 1.7$ & $8.3 \pm 2.2$ & $11.3 \pm 4.3$ & $11.7 \pm 1.5$ \\
\hline & Shape & Spheres & Quasi spherical & Faceted & Faceted & Cubes \\
\hline \multirow[b]{2}{*}{$\mathrm{FeSt}_{3, \mathrm{~d}}$} & Size $(\mathrm{nm})$ & $9.2 \pm 1.5$ & $9.8 \pm 1.4$ & $15.3 \pm 1.8$ & $20 \pm 1.9 / 14 \pm 1.4$ & $13.9 \pm 2.2$ \\
\hline & Shape & Spheres & $\begin{array}{l}\text { Quasi spherical } \\
\text { (M)/Octahedrons@ }\end{array}$ & Cubes & Cubes (M)/Plates (m) & Elongated cubes \\
\hline
\end{tabular}

For plates: $\mathrm{L}$ for length and $\mathrm{t}$ for thickness.

As Figure 1 and Table 2 demonstrate clearly, the introduction of $\mathrm{NaOl}$ in the reactant media has an effect on the shape of NPs. The shape of the synthesized NPs being purely isotropic (spherical) only when sole $\mathrm{OA}$ is used as ligand. $\mathrm{NaOl}$, even if added in low amount, triggers effectively the shape of NPs towards faceted shapes. However, the evolution of the shape with the amount of $\mathrm{NaOl}$ is not the same for all iron stearates and depends strongly on the nature of stearates, $\mathrm{FeSt}_{2}$ and $\mathrm{FeSt}_{3}$, and on their hydration degree.

Interestingly, specific shapes are preferentially obtained from a given precursor structure. At low $\mathrm{NaOl} / \mathrm{OA}$ ratio $(20 / 80)$, less rounded NPs are obtained for all precursors. When this ratio increases, 
$\mathrm{FeSt}_{2}$ and FeSt $\mathrm{t}_{2, \mathrm{~d}}$ allowed to easily obtain nanoplates while that was not possible with $\mathrm{FeSt}_{3}$ and $\mathrm{FeSt}_{3, \mathrm{~d}}$ that led preferentially and quite easily to nanocubes.

For a given $\mathrm{NaOl} / \mathrm{OA}$ ratio, dehydrated precursors demonstrated to form sharper anisotropic morphologies compared to the hydrated precursors. Nonetheless, it was possible to improve the shape definition with hydrated precursors by increasing the part of $\mathrm{NaOl}$ in the synthesis. That is illustrated in Figure 1 with $\mathrm{FeSt}_{3, \mathrm{~d}}$ who led to cubes from a 50/50 NaOl/OA ratio while $\mathrm{FeSt}_{3}$ required a $100 / 0$ ratio.

This study allows to conclude on two points for the shape control of IONPS.

Firstly, hydration is actually a major parameter as hydrated precursors requested a larger amount of $\mathrm{NaOl}$ to tune the shape compared to their dehydrated version. This confirms our previous observation [45] that one parameter, which hampers the formation of well-defined anisotropic shapes is the lower availability of the oleate $\left(\mathrm{Ol}^{-}\right)$ligands, due to their interaction with water molecules. It is well-known that $\mathrm{NaOl}$ easily forms micelles with water [54], which would reduce the amount of $\mathrm{NaOl}$ that can interact with a nucleus to trigger the growth of given shape. That point explains the observation made with $\mathrm{FeSt}_{3}$ precursors and the ratio required to reach the cubic morphology.

Secondly, at a given ratio, precursors with a different structure (number of stearate chains) will lead to different shapes regardless of their hydration degree. Both $\mathrm{FeSt}_{3}$ precursors tend to form cubes whereas plates are observed for FeSt 2 .

The dependence of the shape from precursor nature requires at first to consider the theory behind formation of cubes and plates and involving the effect of the nature of the ligand. According to literature, the theory of the shape control through ligand absorption is quite simple. The crystallographic planes of fcc materials, such as magnetite, do not present the same surface energy $\gamma$. Typically, the ranking established from the lowest energy planes is $\gamma_{\{111\}}<\gamma_{\{100\}}<\gamma_{\{110\}}<\gamma_{\{\mathrm{hkl}\}}$ (with $\mathrm{hkl}>1$ ) $[33,34]$. When a nucleus is formed, it should be thus enclosed by the $\{111\}$ planes that present the lowest surface energy. Thus, a cube which is enclosed by $\{100\}$ planes would not be favored. But as for a given volume, the surface of a cube is lower than the one of an octahedron. The stable nucleus is thus a compromise with the presence of both planes families to reduce the surface energy: The cuboctahedron. Depending on the synthesis conditions, twin defects can also occur in the nucleus. The presence of defect in the nucleus will have a major effect on the final shape of the nanocrystal. For example, a mirror (111) plane can lead to flat nanoparticles [35]. The nucleus shape and structure appear thus major for the further shape control $[55,56]$. The role of the ligands in the shape control has been ascribed to the tuning of growth rate of certain planes of nuclei $[23,28]$, e.g., the adsorption of a ligand on $\{111\}$ planes of a cuboctahedron nucleus will reduce their growth rate. The $\{100\}$ planes will grow faster leading to their disappearance. The final shape will then be an octahedron. Rath and al [36] showed through simulation that the $\{111\}$ plane family of magnetite displays the most active surface for adsorption than the $\{311\}$ and $\{110\}$. When a chelating ligand, such as oleate, is present, it would then adsorb on the $\{111\}$ planes of the nuclei reducing its growth rate.

Whereas it has been reported that the synthesis of cubes is explained by the selective adsorption of $\mathrm{Ol}^{-}$ligand on nuclei controlling thus the cubic growth, the synthesis mechanism of iron oxide nanoplates is not clearly elucidated and their synthesis is still a challenge. Most reported nanoplates have been synthesized by hydrothermal process, but some nanoplates have been synthesized by thermal decomposition of iron oleate $(\mathrm{FeOl})$ in presence of $\mathrm{NaOl}$ in octadecene $[24,57,58]$. By tuning the molar ratio of $\mathrm{NaOl} / \mathrm{FeOl}$ in octadecene solvent, Zhou et al. [12] obtained $\mathrm{Fe}_{3} \mathrm{O}_{4}\{111\}$ facet exposed nanoplates, truncated octahedrons, and tetrahedrons, and reported the predominant role of $\mathrm{NaOl}$ in preserving $\mathrm{Fe}_{3} \mathrm{O}_{4}\{111\}$ facets [12]. The adsorption of $\mathrm{Ol}^{-}$on the $\mathrm{Fe}_{3} \mathrm{O}_{4}\{111\}$ facet is more favorable than that on the $\mathrm{Fe}_{3} \mathrm{O}_{4}\{100\}$ facet. As a result, the growth on other facets is faster than that on the $\mathrm{Fe}_{3} \mathrm{O}_{4}\{111\}$ facet, which results in the preservation of $\mathrm{Fe}_{3} \mathrm{O}_{4}\{111\}$ facets in the products. Palchoudhury et al. [58] reported from a similar system that the formation of different-shaped NPs (including nanoplates) was achieved by controlling the nucleus concentration and growth rate and the nanoplates formation 
was attributed to the presence of a residual product from the precursor reaction and diffusional growth conditions.

In our case, the main difference between $\mathrm{FeSt}_{2}$ and $\mathrm{FeSt}_{3}$ are their water content and the amount of stearate chains, which is higher with $\mathrm{FeSt}_{3}$ than $\mathrm{FeSt}_{2}$. Moreover, we have reported previously [45] different decomposition kinetics with a decomposition of $\mathrm{FeSt}_{2}$ on a lower range of temperature than $\mathrm{FeSt}_{3}$ indicating that nucleation was favored with $\mathrm{FeSt}_{2}$ while growth was dominant for $\mathrm{FeSt}_{3}$. These two points could explain the role of the nature of the precursor on the NPs shape. In order to synthesize nanocubes, the growth step has to be controlled and sufficient amount of deprotonated carboxylic acid based/chelating ligands (i.e., oleate and/or stearate) need to be present in the reaction media to drive the growth. That is why FeSt 3 precursor is optimal as it favors the nuclei growth over nucleation and provide more stearate chains and thus chelating ligands from its decomposition than $\mathrm{FeSt}_{2}$. In the case of the nanoplates, the control of the nucleation step seems to be central to get a flat nucleus. $\mathrm{FeSt}_{2}$ favoring the nucleation with its faster decomposition is then the most appropriate precursor. Although the nature of the precursor is major for the nanoplate shape production, the right ratio of ligands needs to be introduced. A precise ratio of binary surfactants have been reported for the formation of gold nanoplates [55] or iron oxide [58]. As oleic acid is adsorbed less strongly (OA is a universal stabilizer of each facet [12]) than deprotonated carboxylic acid/chelating ligands on specific faces of nuclei, their different adsorption on specific faces should also drive the growth towards the nanoplate shape.

The nanocubes and nanoplates are very interesting for biomedical applications, due to their shape anisotropy. Yet, the shapes obtained in this part could be optimized in order to get a properly defined shaped before investigating their structural properties.

\subsection{An Optimization of the Cubic Shape NPs Leading to Octopod Shape NPs}

The optimization of the cubic shape of the NPs was realized in two steps. At first, the influence of the heating rate on the cubic morphology was investigated. Indeed, the kinetic conditions would favor the cubic shape [39]. Several reports [24,38-40] showed that high heating rates were rather used for nanocube synthesis. The heating rate has been varied by using hydrated $\mathrm{FeSt}_{2}$ (cheapest and easiest precursor to synthesize) at a NaOl/OA ratio of 50/50. Figure S2 presents the TEM images of syntheses, which have led to faceted NPs with no specific shapes with a heating rate of $1{ }^{\circ} \mathrm{C} / \mathrm{min}$ and rounded corner cubes with a heating rate of $5^{\circ} \mathrm{C} / \mathrm{min}$, confirming that a high heating rate is favorable to the cubic shape in our synthesis conditions. The increase of the heating rate led also to a decrease in the NPs mean size from $13.5 \pm 2.5 \mathrm{~nm}$ for $1{ }^{\circ} \mathrm{C} / \mathrm{min}$ to $11.8 \pm 1.8 \mathrm{~nm}$ for $5{ }^{\circ} \mathrm{C} / \mathrm{min}$.

Secondly, the synthesis of nanocubes with $\mathrm{FeSt}_{3}$ conducted to rounded corner cubes by comparison with the oleate precursor that led to nanocubes with straight faces. The hypothesis being that the shape with round corners originated from a lack of the surfactant $(\mathrm{NaOl})$ involved in the cubic growth control (in agreement with the presence of water molecules in the precursor). The objective was here to introduce more $\mathrm{NaOl}$ (i.e., increasing the ratio $\mathrm{NaOl} / \mathrm{FeSt}_{3}$ ) to provide more ligands to control the growth of flat faces. Therefore, the ratio Precursor/Ligands was here increased from 0.75 to 1 just by adjusting the amount of $\mathrm{FeSt}_{3}$. Furthermore, a high heating ramp of $15^{\circ} \mathrm{C} / \mathrm{min}$ was chosen to ensure the growth step to happen in the kinetic regime, i.e., fast enough to favor the cubic morphology, which is not favored in the thermodynamic controlled conditions. TEM image in Figure 2 shows that such modification of the synthesis protocol allowed improving the definition of the nanocube shape and nanocubes with a mean size of $14.5 \pm 1.6 \mathrm{~nm}$ (NC15) were obtained. 


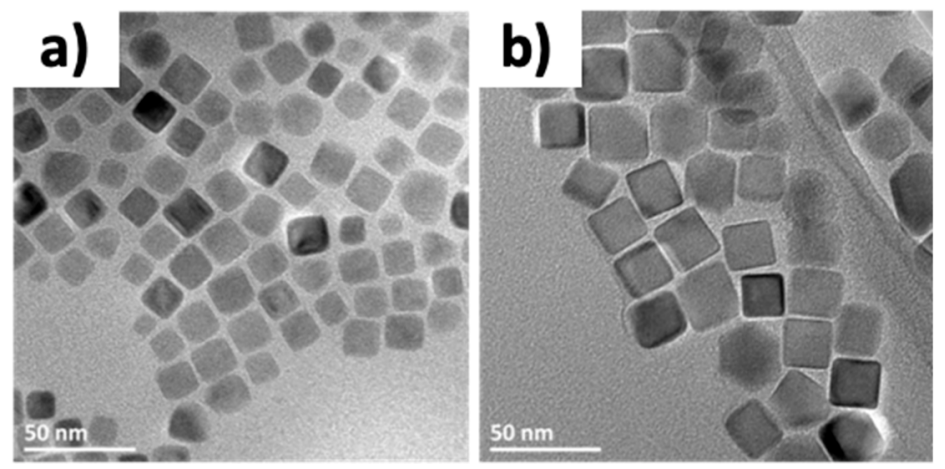

Figure 2. Transmission electron microscopy (TEM) images of nanocubes synthesized from $\mathrm{FeSt}_{3}$ using adapted Kovalenko protocol (a), and using the optimized protocol (b).

The XRD pattern of NC15 (Figure S3a) indicated that nanocubes are made of a core of wüstite $\mathrm{Fe}_{1-\mathrm{x}} \mathrm{O}$ coated with a shell of spinel, as already observed [48,49]. Considering our previous results with nanospheres, such composition may be related to the competition between the growth rate and the oxidation kinetic of the $\mathrm{Fe}_{1-x} \mathrm{O}$ nuclei within this temperature range. Lattice parameters calculated for NC15 from Rietveld refinement gave a parameter of $8.392 \pm 1 \AA$ for the shell close to that of stoichiometric magnetite (0.8396 nm, JCPDS file 19-629) and of $4.237 \pm 1 \AA$ for the wüstite core. From an earlier study on nanocubes synthesized using iron oleate as precursor [48] and from recent results to obtain nanocubes or nanospheres with a homogeneous spinel composition $[48,59]$, the first formed phase under the used experimental conditions should be the $\mathrm{Fe}_{1-\mathrm{x}} \mathrm{O}$ one, which is then oxidized with time. The shell displayed generally a lattice parameter close or slightly larger to that of stoichiometric magnetite, which is ascribed to an epitaxial matching between both phases and strains, generated by the oxidation of wüstite and the lattice parameter of the wüstite phase strongly depended on its oxidation state. According to the formula $\mathrm{Fe}_{1-\mathrm{x}} \mathrm{O}$, the iron content $x$ can be easily calculated from the cell parameter using the relationship $a_{\mathrm{FexO}}=0.3856+0.0478 x$ [60]. The result gives $x$ value of 0.8 , which suggest that the wüstite core has been formed in strong reducing conditions and even that the current synthesis conditions would be stronger than those used in our previous study (max 0.83) [48]. The wüstite phase was shown to be metastable and to transform into wüstite with higher iron content and spinel phases through an oxidation mechanism with ageing time in former nanocubes [48]. The oxidation mechanism and the epitaxial growth resulted in the diffusion of cations and vacancies that generated high strains at the $\mathrm{Fe}_{1-\mathrm{x}} \mathrm{O} / \mathrm{Fe}_{3-\mathrm{x}} \mathrm{O}_{4}$ interface and in the $\mathrm{Fe}_{3-\mathrm{x}} \mathrm{O}_{4}$ shell. Infra-red (IR) spectra (Figure S3) showed that the $\mathrm{Fe}-\mathrm{O}$ bands are characteristic of a slightly oxidized magnetite. The broad band maximum is between those of the stoichiometric magnetite and maghemite $\left(\gamma-\mathrm{Fe}_{2} \mathrm{O}_{3}\right)$ phases [31].

Different synthesis conditions have been tested in order to obtain nanocubes with a homogeneous composition in the spinel phase (i.e., without a wüstite core): Bubbling of air, other solvents than alkene; among others. Unfortunately, a loss of the cubic shape was generally observed. Indeed, the synthesis conditions of the cubic shaped NPs are constrained and these reducing and strict conditions should affect the oxidation kinetic. It has been often observed that such a combination of $\mathrm{NaOl}$ and $\mathrm{OA}$ leads to core-shell cubes, which suggested a strong influence of the amount of oleate chains in agreement with our previous observations during the synthesis of nanocubes using the iron oleate precursor [48].

Nevertheless, other published methods have reported nanocubes with a spinel composition $[20,21,39,43]$. The method developed by Pellegrino and al [20] using a mixture of squalene and dibenzylether (DBE) as a solvent has led to nanocubes with a homogeneous composition. They reported that the products of decomposition of DBE were responsible for the control of the shape of NPs [21]. We adapted the Pellegrino team's protocol using iron (III) stearate and DBE as solvent and it led to NPs with a cubic shape with elongated corners named octopods 
(Figure 3). Such octopods display interestingly a homogeneous spinel composition indicating that the reaction media was oxidizing by comparison with our one.
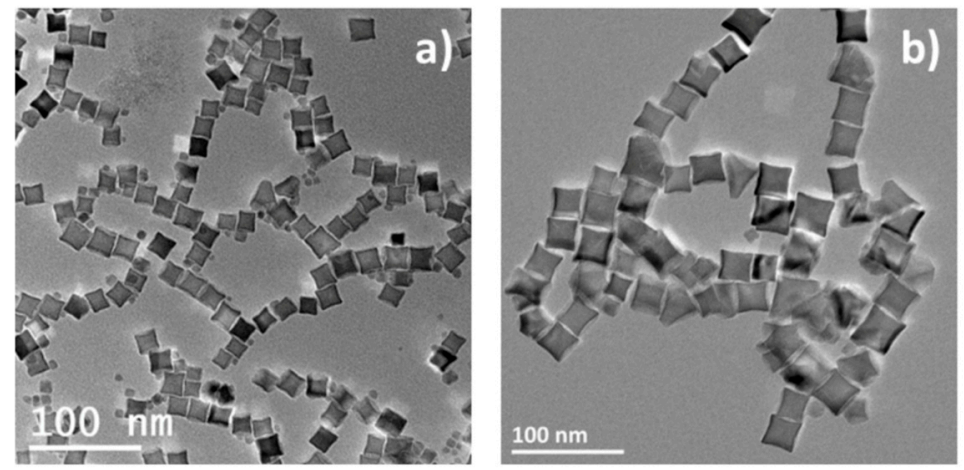

Figure 3. Transmission electron microscopy (TEM) images of the $18 \mathrm{~nm}$ octopods (a) and $28 \mathrm{~nm}$ octopods (b).

Such an octopod shape would originate from a difference in the kinetics of the reaction. It has been explained that when the cubic NP is formed, if the number of monomers that precipitated on the surface is large enough, it will preferentially remain on the corners that present the higher surface energy instead of diffusing on the whole surface of the NPs. As the heating rate up to the growth step is rather fast $\left(10^{\circ} \mathrm{C} / \mathrm{min}\right)$, this could be what is at work here. In Pellegrino's protocol, the ratio DBE:squalene was demonstrated to drive size control. The more DBE was introduced, the smaller the NPs.

In our synthesis conditions, the size has been tuned by adapting the FeSt:OA ratio and mean sizes of $17.2 \pm 2.2 \mathrm{~nm}$ (NO18) for a ratio of 1:3 and of $27.8 \pm 4.2 \mathrm{~nm}$ (NO28) for a ratio of 1:4.5 were thus synthesized. These objects are quite interesting as the presence of the elongated corner should increase the shape anisotropy of NPs. Their homogeneous spinel composition was confirmed by XRD refinement (Figure S3c) with a lattice parameter of $8.364 \AA$ for NO18 and of $8.370 \AA$ for NO28. Those lattice parameters values in-between those of magnetite and maghemite $(0.8346 \mathrm{~nm}$, JCPDS file 39-1346) indicated an oxidation of both NO. The position of the maximum of the broad Fe-O band (Figure S3d) between that at $580 \mathrm{~cm}^{-1}$ of magnetite and that at $630 \mathrm{~cm}^{-1}$ of maghemite is also in agreement with an oxidized magnetite composition.

Due to the anisotropic shape, the crystallite size has been determined from Rietveld refinement as a function of the (hkl) planes (Table 3). The crystallites size depends on the size with the largest directions being $<400>$ and $<511>$ for NO28 and $<220>$ and $<440>$ for NO18. The longest directions for NO18 are thus the one belonging to the $<110>$ family implying that the diagonal of the face is longer than the diagonal of the assimilated cube. For NO28, the longest direction is the $<400>$ one followed by the $<511>$ one which indicates a different exposition of crystallographic planes in the corner. For both size NO, the measured crystallite size matches with the size determined from TEM images with $15 \pm 1 \mathrm{~nm}<220>$ for NO18 and $25 \pm 1 \mathrm{~nm}<400>$ for NO28.

Table 3. TEM size and lattice parameter and crystallites size determined from X-ray diffraction (XRD) refinement.

\begin{tabular}{|c|c|c|c|c|c|c|c|c|c|c|c|c|c|}
\hline \multirow{2}{*}{ Sample } & \multirow{2}{*}{ TEM (nm) } & \multirow{2}{*}{$\begin{array}{c}\text { Lattice Parameter } \\
\text { (§̊) }\end{array}$} & \multicolumn{11}{|c|}{ Crystallite Size According to Crystallographic Direction $\pm 1(\mathrm{~nm})$} \\
\hline & & & 220 & 311 & 222 & 400 & 331 & 422 & 511 & 333 & 440 & 531 & 442 \\
\hline NO18 & $17.2 \pm 2.2$ & 8.364 & 15 & 13 & 11 & 11 & 11 & 12 & 13 & 11 & 15 & 12 & 11 \\
\hline $\mathrm{NO} 28$ & $27.8 \pm 4.2$ & 8.370 & 19 & 20 & 13 & 25 & 18 & 17 & 23 & 12 & 19 & 21 & 16 \\
\hline NPl17 & $16.7 \pm 5.2$ & 8.384 & 11 & 9 & 17 & 8 & 11 & 10 & 8 & 17 & 11 & 9 & 12 \\
\hline
\end{tabular}

\subsection{Exploring the Nanoplates Synthesis}

Previously, all synthesis conditions led to the same plate thickness (around $6 \mathrm{~nm}$ ). To tune this thickness in order to modulate the properties of the objects, the heating rate has been varied. With a 
$\mathrm{NaOl} / \mathrm{OA}$ ratio of $80 / 20$ and whatever the heating rate (Figure S4), nanoplates are obtained. The mean sizes are for $1{ }^{\circ} \mathrm{C} / \mathrm{min}: 1=16.7 \pm 5.2 \mathrm{~nm}$ and $\mathrm{t}=8.6 \pm 1.7 \mathrm{~nm}$ and for $5^{\circ} \mathrm{C} / \mathrm{min}: 1=16.6 \pm 4.9 \mathrm{~nm}$ and $\mathrm{t}=6.1 \pm 1 \mathrm{~nm}$ ): The thickness decreases with the increase of the heating rate. An increase in the heating rate up to $10{ }^{\circ} \mathrm{C} / \mathrm{min}$ promoted partly the formation of cubic NPs (Figure S4). At $10{ }^{\circ} \mathrm{C} / \mathrm{min}$, the length decreased $(15.8 \pm 4.5 \mathrm{~nm})$ and the thickness is in between the two former values $(7.1 \pm 1.4 \mathrm{~nm})$. Yet, the variation is not significant in regard of the measurement error. Thus, there is no variation of the thickness with the heating rate.

As the nanoplates shape did not present the same dependence on the heating rate than the cubic one, it confirms that the main step to control the nanoplates shape is not the growth step (case of nanocubes), but rather the nucleation one. We have thus introduced a "nucleation step" in our experimental conditions of nanoplates synthesis and we have varied the "nucleation step" temperature. When this step was removed or was below $200^{\circ} \mathrm{C}$, nanoplates were observed to form (Figure 4). Above $200{ }^{\circ} \mathrm{C}$, the nanoplate's occurrence decreased. Moreover, when the duration of the step was increased from 10 to $30 \mathrm{~min}$ at $210{ }^{\circ} \mathrm{C}$, no plates were observed at all (Figure 4 ). That confirms the importance of the nucleation step.
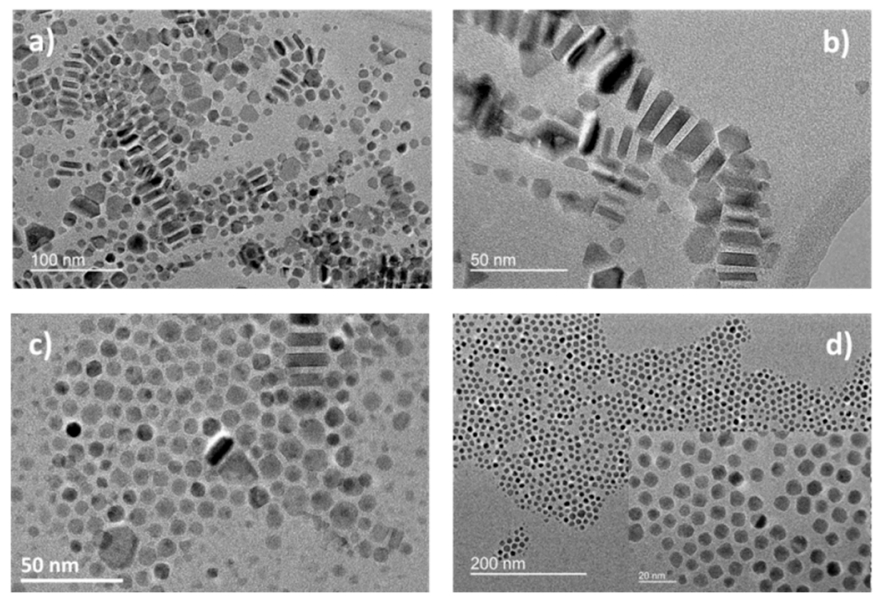

Figure 4. Influence of the germination step with the ratio 80/20: No germination step (a) germination step at (b) $190{ }^{\circ} \mathrm{C}$ for $10 \mathrm{~min}$; (c) $210^{\circ} \mathrm{C}$ for $10 \mathrm{~min}$, and (d) $210^{\circ} \mathrm{C}$ for $30 \mathrm{~min}$.

High resolution TEM (HR-TEM) and 3D TEM tomography have already been performed earlier on nanocubes to confirm their shape [48]. They were performed here on the nanoplates as this shape has been rarely reported.

The 3D TEM tomography images in Figure 5 confirmed the flat shape of nanoplates and showed that the fully formed nanoplates are not perfectly flat, but concave. The smaller NPs are rather convex confirming the spherical profile to reduce the surface energy. The plates studied here have a $17.5 \pm 4.4 \mathrm{~nm}$ length and a $6.3 \pm 1.3 \mathrm{~nm}$ thickness (nanoplates from hydrated FeSt 2 ). HR-TEM images (Figure 5) showed that the long face of the plate is made out of $\{111\}$ planes and the sides are made out of $\{220\}$ planes. 

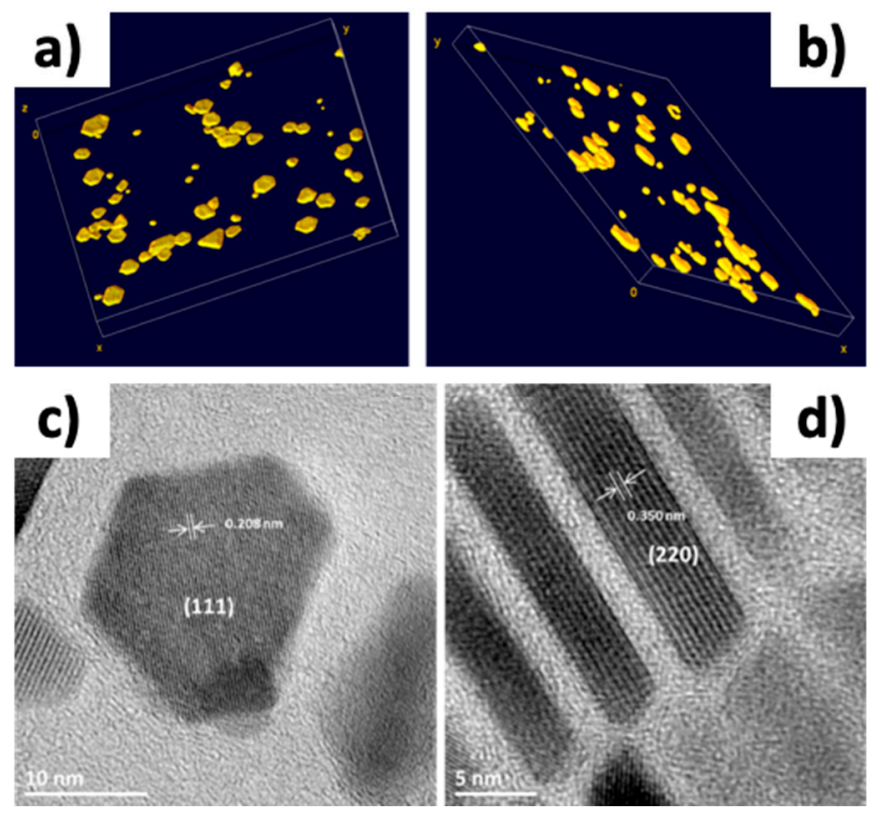

Figure 5. 3D TEM reconstruction of the nanoplates $(\mathbf{a}, \mathbf{b})$ and high resolution transmission electron microscopy (HR-TEM) images of the long face of a platelets (c); and of the side (d).

The XRD pattern (Figure S3c) presented the XRD peaks characteristic of a spinel phase with a lattice parameter of $8.384 \pm 1 \AA$, determined through Rietveld refinement. The nanoplates are thus slightly oxidized in agreement with the IR spectrum (Figure S3e) where a broad band with a maximum at $580 \mathrm{~cm}^{-1}$ (close to the magnetite one) is observed. The crystallite size according to specific crystallographic directions was also determined by Rietveld refinement (Table 3). The crystallite size of $17 \pm 1 \mathrm{~nm}$ in the direction $<111>$ is in agreement with the TEM size $(16.7 \pm 5.2 \mathrm{~nm})$, but also with a $2 \mathrm{D}$ growth formation mechanism. As most of the nanoplates tended to lay flat during the XRD acquisition. It is hard to clearly see the planes within the thickness. Yet the value of $8 \pm 1 \mathrm{~nm}$ close to the one measured for the thickness would imply that the planes (400), (511) enclose the sides of the plates.

We have shown above that high heating rates were required to favor the cubic shape when it was not the case for the nanoplate formation. Contrarily to the cubes, they do not present a reduced phase core of wüstite. However, plates whose thickness is very small should be easily oxidized when exposed to air despite the growth kinetics.

\section{Conclusions}

The influence of the structure of the precursor on the shape of the NPs has been scarcely investigated in the literature. We have thus studied the thermal decomposition of hydrated and dehydrated $\mathrm{FeSt}_{2}$ and $\mathrm{FeSt}_{3}$ as a function of the $\mathrm{NaOl} / \mathrm{OA}$ ratio introduced in the reaction media. We have mainly confirmed that (1) NaOl triggered effectively the NPs shape formation, that (2) the nature of the precursor affects the shape with $\mathrm{FeSt}_{2}$ favoring the formation of nanoplates whereas $\mathrm{FeSt}_{3}$ favored that of nanocubes and that (3) the hydration is deleterious for the formation of anisotropic shapes and more $\mathrm{NaOl}$ is needed to form anisotropic shaped NPs from highly hydrated precursors, most likely due to the interaction of ligands with water to form micelles. Thus, dehydrated precursors allowed a better control over the shape. The formation of nanocubes was confirmed to be driven by the amount of sodium oleate and the heating rate. The control of the monomer formation at the nucleation step was found very important for the nanoplate synthesis. Therefore, the nucleation step appeared very important to direct the nanoplate formation conjointly with a precise $\mathrm{NaOl} / \mathrm{OA}$ ratio. Further work will focus on the study the magnetic properties of the obtained shapes. 
Supplementary Materials: The following are available online at http:/ /www.mdpi.com/2079-4991/8/11/881/s1, Figure S1: Size distribution of NPs determined from TEM diameter measurement over 300 NPS, Figure S2: TEM images of the decomposition of hydrated $\mathrm{FeSt}_{2}$ at a $\mathrm{NaOl} / \mathrm{OA}$ ratio of $50 / 50$ with a heating rate of (a) $1^{\circ} \mathrm{C} / \mathrm{min}$ and (b) $5{ }^{\circ} \mathrm{C} / \mathrm{min}$, Figure S3: XRD refinement of NC15 (a), NPl (b), NO28 (c), IR spectra of NC (blue), NPl (yellow) and NO28 (green) (d) and typical IR spectra of slightly oxidized magnetite and maghemite (e), Figure S4: TEM images of the decomposition of hydrated $\mathrm{FeSt}_{2}$ at a NaOl/OA Ratio $80 / 20$ (a) $1^{\circ} \mathrm{C} / \mathrm{min}$, (b) $5^{\circ} \mathrm{C} / \mathrm{min}$ and (c) 10 ${ }^{\circ} \mathrm{C} / \mathrm{min}$.

Author Contributions: For research articles with several authors, a short paragraph specifying their individual contributions must be provided. The following statements should be used "Conceptualization, S.B.-C. and G.C.; Investigation, G.C., C.K., F.P., D.I., C.B.-A., S.M., C.L., D.M, B.P.; Resources, O.E.; Writing-Original Draft Preparation, G.C.; Writing-Review \& Editing, S.B.-C.; Supervision, S.B.-C.; Project Administration, S.B.-C.; Funding Acquisition, S.B.-C.

Funding: This research was funded by The Region Alsace, France, and the Labex Chimie des Systemes Complexes, University of Strasbourg, France (doctoral fellowship to Geoffrey Cotin). This research project was also co-funded by Labex CSC, Alsace contre le cancer, INCA (project PRTK14, THERAMAG 2014-225) and the INTERREG project NANOTRANSMED.

Acknowledgments: The authors thank COST Action RADIOMAG (TD1402) supported by COST (European Cooperation in Science and Technology).

Conflicts of Interest: The authors declare no conflicts of interest.

\section{References}

1. Tartaj, P.; Morales, M.P.; Gonzalez-Carreño, T.; Veintemillas-Verdaguer, S.; Serna, C.J. The Iron Oxides Strike Back: From Biomedical Applications to Energy Storage Devices and Photoelectrochemical Water Splitting. Adv. Mater. 2011, 23, 5243-5249. [CrossRef] [PubMed]

2. Zeng, H.; Black, C.T.; Sandstrom, R.L.; Rice, P.M.; Murray, C.B.; Sun, S. Magnetotransport of magnetite nanoparticle arrays. Phys. Rev. B 2006, 73, 020402. [CrossRef]

3. Laurent, S.; Forge, D.; Port, M.; Roch, A.; Robic, C.; Vander Elst, L.; Muller, R.N. Magnetic Iron Oxide Nanoparticles: Synthesis, Stabilization, Vectorization, Physicochemical Characterizations, and Biological Applications. Chem. Rev. 2008, 108, 2064-2110. [CrossRef] [PubMed]

4. Frey, N.A.; Peng, S.; Cheng, K.; Sun, S. Magnetic nanoparticles: synthesis, functionalization, and applications in bioimaging and magnetic energy storage. Chem. Soc. Rev. 2009, 38, 2532-2542. [CrossRef] [PubMed]

5. Lu, A.-H.; Salabas, E.L.; Schüth, F. Magnetic Nanoparticles: Synthesis, Protection, Functionalization, and Application. Angew. Chem. Int. Ed. 2007, 46, 1222-1244. [CrossRef] [PubMed]

6. Williams, G.V.M.; Prakash, T.; Kennedy, J.; Chong, S.V.; Rubanov, S. Spin-dependent tunnelling in magnetite nanoparticles. J. Magn. Magn. Mater. 2018, 460, 229-233. [CrossRef]

7. Prakash, T.; Williams, G.V.M.; Kennedy, J.; Rubanov, S. Formation of magnetic nanoparticles by low energy dual implantation of $\mathrm{Ni}$ and $\mathrm{Fe}$ into $\mathrm{SiO}_{2}$. J. Alloys Compd. 2016, 667, 255-261. [CrossRef]

8. Kennedy, J.; Leveneur, J.; Williams, G.V.M.; Mitchell, D.R.G.; Markwitz, A. Fabrication of surface magnetic nanoclusters using low energy ion implantation and electron beam annealing. Nanotechnology 2011, 22, 115602. [CrossRef] [PubMed]

9. Sayed, F.N.; Polshettiwar, V. Facile and Sustainable Synthesis of Shaped Iron Oxide Nanoparticles: Effect of Iron Precursor Salts on the Shapes of Iron Oxides. Sci. Rep. 2015, 5, 9733. [CrossRef] [PubMed]

10. Polshettiwar, V.; Baruwati, B.; Varma, R.S. Self-Assembly of Metal Oxides into Three-Dimensional Nanostructures: Synthesis and Application in Catalysis. ACS Nano 2009, 3, 728-736. [CrossRef] [PubMed]

11. De Montferrand, C.; Hu, L.; Milosevic, I.; Russier, V.; Bonnin, D.; Motte, L.; Brioude, A.; Lalatonne, Y. Iron oxide nanoparticles with sizes, shapes and compositions resulting in different magnetization signatures as potential labels for multiparametric detection. Acta Biomater. 2013, 9, 6150-6157. [CrossRef] [PubMed]

12. Joshi, H.M.; Lin, Y.P.; Aslam, M.; Prasad, P.V.; Schultz-Sikma, E.A.; Edelman, R.; Meade, T.; Dravid, V.P. Effects of shape and size of cobalt ferrite nanostructures on their MRI contrast and thermal activation. J. Phys. Chem. C 2009, 113, 17761-17767. [CrossRef] [PubMed]

13. Smolensky, E.D.; Park, H.-Y.E.; Zhou, Y.; Rolla, G.A.; Marjańska, M.; Botta, M.; Pierre, V.C. Scaling laws at the nanosize: the effect of particle size and shape on the magnetism and relaxivity of iron oxide nanoparticle contrast agents. J. Mater. Chem. B 2013, 1, 2818. [CrossRef] [PubMed] 
14. Lee, N.; Choi, Y.; Lee, Y.; Park, M.; Moon, W.K.; Choi, S.H.; Hyeon, T. Water-Dispersible Ferrimagnetic Iron Oxide Nanocubes with Extremely High r 2 Relaxivity for Highly Sensitive in Vivo MRI of Tumors. Nano Lett. 2012, 12, 3127-3131. [CrossRef] [PubMed]

15. Zhao, Z.; Zhou, Z.; Bao, J.; Wang, Z.; Hu, J.; Chi, X.; Ni, K.; Wang, R.; Chen, X.; Chen, Z.; et al. Octapod iron oxide nanoparticles as high-performance $\mathrm{T}_{2}$ contrast agents for magnetic resonance imaging. Nat. Commun. 2013, 4, 2266. [CrossRef] [PubMed]

16. Sathya, A.; Guardia, P.; Brescia, R.; Silvestri, N.; Pugliese, G.; Nitti, S.; Manna, L.; Pellegrino, T. Co $\mathrm{C}_{x} \mathrm{Fe}_{3-\mathrm{x}} \mathrm{O}_{4}$ Nanocubes for Theranostic Applications: Effect of Cobalt Content and Particle Size. Chem. Mater. 2016, 28, 1769-1780. [CrossRef]

17. Blanco-Andujar, C.; Walter, A.; Cotin, G.; Bordeianu, C.; Mertz, D.; Felder-Flesch, D.; Begin-Colin, S. Design of iron oxide-based nanoparticles for MRI and magnetic hyperthermia. Nanomedicine 2016, 11, 1889-1910. [CrossRef] [PubMed]

18. Xie, W.; Guo, Z.; Gao, F.; Gao, Q.; Wang, D.; Liaw, B.; Cai, Q.; Sun, X.; Wang, X.; Zhao, L. Shape-, size- and structure-controlled synthesis and biocompatibility of iron oxide nanoparticles for magnetic theranostics. Theranostics 2018, 8, 3284-3307. [CrossRef] [PubMed]

19. Nemati, Z.; Alonso, J.; Rodrigo, I.; Das, R.; Garaio, E.; García, J.Á.; Orue, I.; Phan, M.-H.; Srikanth, H. Improving the Heating Efficiency of Iron Oxide Nanoparticles by Tuning Their Shape and Size. J. Phys. Chem. C 2018, 122, 2367-2381. [CrossRef]

20. Guardia, P.; Di Corato, R.; Lartigue, L.; Wilhelm, C.; Espinosa, A.; Garcia-Hernandez, M.; Gazeau, F.; Manna, L.; Pellegrino, T. Water-Soluble Iron Oxide Nanocubes with High Values of Specific Absorption Rate for Cancer Cell Hyperthermia Treatment. ACS Nano 2012, 6, 3080-3091. [CrossRef] [PubMed]

21. Guardia, P.; Riedinger, A.; Nitti, S.; Pugliese, G.; Marras, S.; Genovese, A.; Materia, M.; Lefevre, C.; Manna, L.; Pellegrino, T. One pot synthesis of monodisperse water soluble iron oxide nanocrystals with high values of specific absorption rate. J. Mater. Chem. B 2014, 2, 4426-4434. [CrossRef]

22. Wetterskog, E.; Tai, C.-W.; Grins, J.; Bergström, L.; Salazar-Alvarez, G. Anomalous Magnetic Properties of Nanoparticles Arising from Defect Structures: Topotaxial Oxidation of $\mathrm{Fe}_{1-\mathrm{x}} \mathrm{O} \mid \mathrm{Fe}_{3-\delta} \mathrm{O}_{4}$ Core IShell Nanocubes to Single-Phase Particles. ACS Nano 2013, 7, 7132-7144. [CrossRef] [PubMed]

23. Wetterskog, E.; Agthe, M.; Mayence, A.; Grins, J.; Wang, D.; Rana, S.; Ahniyaz, A.; Salazar-Alvarez, G.; Bergström, L. Precise control over shape and size of iron oxide nanocrystals suitable for assembly into ordered particle arrays. Sci. Technol. Adv. Mater. 2014, 15, 2802. [CrossRef] [PubMed]

24. Zhou, Z.; Zhu, X.; Wu, D.; Chen, Q.; Huang, D.; Sun, C.; Xin, J.; Ni, K.; Gao, J. Anisotropic Shaped Iron Oxide Nanostructures: Controlled Synthesis and Proton Relaxation Shortening Effects. Chem. Mater. 2015, 27, 3505-3515. [CrossRef]

25. Sun, S.; Zeng, H. Size-controlled synthesis of magnetite nanoparticles. J. Am. Chem. Soc. 2002, 124, 8204-8205. [CrossRef] [PubMed]

26. Hyeon, T.; Lee, S.S.; Park, J.; Chung, Y.; Na, H.B. Synthesis of Highly Crystalline and Monodisperse Maghemite Nanocrystallites without a Size-Selection Process. J. Am. Chem. Soc. 2001, 123, 12798-12801. [CrossRef] [PubMed]

27. Park, J.; An, K.; Hwang, Y.; Park, J.-G.; Noh, H.-J.; Kim, J.-Y.; Park, J.-H.; Hwang, N.-M.; Hyeon, T. Ultra-large-scale syntheses of monodisperse nanocrystals. Nat. Mater. 2004, 3, 891-895. [CrossRef] [PubMed]

28. Kovalenko, M.V.; Bodnarchuk, M.I.; Lechner, R.T.; Hesser, G.; Schäffler, F.; Heiss, W. Fatty Acid Salts as Stabilizers in Size- and Shape-Controlled Nanocrystal Synthesis: The Case of Inverse Spinel Iron Oxide. J. Am. Chem. Soc. 2007, 129, 6352-6353. [CrossRef] [PubMed]

29. Bronstein, L.M.; Huang, X.; Retrum, J.; Schmucker, A.; Pink, M.; Stein, B.D.; Dragnea, B. Influence of Iron Oleate Complex Structure on Iron Oxide Nanoparticle Formation. Chem. Mater. 2007, 19, 3624-3632. [CrossRef]

30. LaMer, V.K.; Dinegar, R.H. Theory, Production and Mechanism of Formation of Monodispersed Hydrosols. J. Am. Chem. Soc. 1950, 72, 4847-4854. [CrossRef]

31. Baaziz, W.; Pichon, B.P.; Fleutot, S.; Liu, Y.; Lefevre, C.; Greneche, J.-M.; Toumi, M.; Mhiri, T.; Begin-Colin, S. Magnetic Iron Oxide Nanoparticles: Reproducible Tuning of the Size and Nanosized-Dependent Composition, Defects, and Spin Canting. J. Phys. Chem. C 2014, 118, 3795-3810. [CrossRef] 
32. Kwon, S.G.; Piao, Y.; Park, J.; Angappane, S.; Jo, Y.; Hwang, N.-M.; Park, J.-G.; Hyeon, T. Kinetics of monodisperse iron oxide nanocrystal formation by "heating-up" process. J. Am. Chem. Soc. 2007, 129, 12571-12584. [CrossRef] [PubMed]

33. Wang, Z.L. Transmission Electron Microscopy of Shape-Controlled Nanocrystals and Their Assemblies. J. Phys. Chem. B 2000, 104, 1153-1175. [CrossRef]

34. Yang, C.; Wu, J.; Hou, Y. $\mathrm{Fe}_{3} \mathrm{O}_{4}$ nanostructures: synthesis, growth mechanism, properties and applications. Chem. Commun. 2011, 47, 5130. [CrossRef] [PubMed]

35. Xia, Y.; Xiong, Y.; Lim, B.; Skrabalak, S.E. Shape-controlled synthesis of metal nanocrystals: simple chemistry meets complex physics? Angew. Chem. Int. Ed. Engl. 2009, 48, 60-103. [CrossRef] [PubMed]

36. Rath, S.S.; Sinha, N.; Sahoo, H.; Das, B.; Mishra, B.K. Molecular modeling studies of oleate adsorption on iron oxides. Appl. Surf. Sci. 2017, 7, 2802. [CrossRef]

37. Guardia, P.; Labarta, A.; Batlle, X. Tuning the Size, the Shape, and the Magnetic Properties of Iron Oxide Nanoparticles. J. Phys. Chem. C 2011, 115, 390-396. [CrossRef]

38. Shavel, A.; Liz-Marzán, L.M. Shape control of iron oxide nanoparticles. Phys. Chem. Chem. Phys. 2009, 11, 3762-3766. [CrossRef] [PubMed]

39. Kim, D.; Lee, N.; Park, M.; Kim, B.H.; An, K.; Hyeon, T. Synthesis of Uniform Ferrimagnetic Magnetite Nanocubes. J. Am. Chem. Soc. 2009, 131, 454-455. [CrossRef] [PubMed]

40. Shavel, A.; Rodríguez-González, B.; Spasova, M.; Farle, M.; Liz-Marzán, L.M. Synthesis and Characterization of Iron/Iron Oxide Core/Shell Nanocubes. Adv. Funct. Mater. 2007, 17, 3870-3876. [CrossRef]

41. Hai, H.T.; Yang, H.T.; Kura, H.; Hasegawa, D.; Ogata, Y.; Takahashi, M.; Ogawa, T. Size control and characterization of wustite (core)/spinel (shell) nanocubes obtained by decomposition of iron oleate complex. J. Colloid Interface Sci. 2010, 346, 37-42. [CrossRef] [PubMed]

42. Kim, D.; Park, J.; An, K.; Yang, N.-K.; Park, J.-G.; Hyeon, T. Synthesis of Hollow Iron Nanoframes. J. Am. Chem. Soc. 2007, 129, 5812-5813. [CrossRef] [PubMed]

43. Yang, H.; Ogawa, T.; Hasegawa, D.; Takahashi, M. Synthesis and magnetic properties of monodisperse magnetite nanocubes. J. Appl. Phys. 2008, 103, 07D526. [CrossRef]

44. Cervadoro, A.; Cho, M.; Key, J.; Cooper, C.; Stigliano, C.; Aryal, S.; Brazdeikis, A.; Leary, J.F.; Decuzzi, P. Synthesis of Multifunctional Magnetic NanoFlakes for Magnetic Resonance Imaging, Hyperthermia, and Targeting. ACS Appl. Mater. Interfaces 2014, 6, 12939-12946. [CrossRef] [PubMed]

45. Cotin, G.; Kiefer, C.; Perton, F.; Boero, M.; Özdamar, B.; Bouzid, A.; Ori, G.; Massobrio, C.; Begin, D.; Pichon, B.; et al. Evaluating the Critical Roles of Precursor Nature and Water Content When Tailoring Magnetic Nanoparticles for Specific Applications. ACS Appl. Nano Mater. 2018, 1, 4306-4316. [CrossRef]

46. Xu, Z.; Shen, C.; Tian, Y.; Shi, X.; Gao, H.-J. Organic phase synthesis of monodisperse iron oxide nanocrystals using iron chloride as precursor. Nanoscale 2010, 2, 1027-1032. [CrossRef] [PubMed]

47. Yin, Y.; Alivisatos, A.P. Colloidal nanocrystal synthesis and the organic-inorganic interface. Nature 2005, 437, 664-670. [CrossRef] [PubMed]

48. Pichon, B.P.; Gerber, O.; Lefevre, C.; Florea, I.; Fleutot, S.; Baaziz, W.; Pauly, M.; Ohlmann, M.; Ulhaq, C.; Ersen, O.; et al. Microstructural and Magnetic Investigations of Wüstite-Spinel Core-Shell Cubic-Shaped Nanoparticles. Chem. Mater. 2011, 23, 2886-2900. [CrossRef]

49. Walter, A.; Billotey, C.; Garofalo, A.; Ulhaq-Bouillet, C.; Lefèvre, C.; Taleb, J.; Laurent, S.; Vander Elst, L.; Muller, R.N.; Lartigue, L.; et al. Mastering the Shape and Composition of Dendronized Iron Oxide Nanoparticles To Tailor Magnetic Resonance Imaging and Hyperthermia. Chem. Mater. 2014, 26, 5252-5264. [CrossRef]

50. Bronstein, L.M.; Atkinson, J.E.; Malyutin, A.G.; Kidwai, F.; Stein, B.D.; Morgan, D.G.; Perry, J.M.; Karty, J.A. Nanoparticles by Decomposition of Long Chain Iron Carboxylates: From Spheres to Stars and Cubes. Langmuir 2011, 27, 3044-3050. [CrossRef] [PubMed]

51. Buck, M.R.; Biacchi, A.J.; Schaak, R.E. Insights into the Thermal Decomposition of Co(II) Oleate for the Shape-Controlled Synthesis of Wurtzite-Type CoO Nanocrystals. Chem. Mater. 2014, 26, 1492-1499. [CrossRef]

52. Rodríguez-Carvajal, J. Recent advances in magnetic structure determination by neutron powder diffraction. Physica B: Condensed Matter 1993, 192, 55-69. [CrossRef]

53. Le Bail, A.; Duroy, H.; Fourquet, J.L. Ab Initio Structure Determination of LiSbWO6 by X-ray Powder Diffraction. Mater. Res. Bull. 1988, 23, 447-452. [CrossRef] 
54. Mahieu, N.; Canet, D.; Cases, J.M.; Boubel, J.C. Micellization of sodium oleate in water-d2 as probed by proton longitudinal magnetic relaxation and self-diffusion measurements. J. Phys. Chem. 1991, 95, 1844-1846. [CrossRef]

55. Tan, T.; Yao, L.; Liu, H.; Li, C.; Wang, C. Precise Control of the Lateral and Vertical Growth of Two-Dimensional Ag Nanoplates. Chem. Eur. J. 2017, 23, 10001-10006. [CrossRef] [PubMed]

56. Gao, D.; Tian, D.; Chong, B.; Zhang, X.; Gao, W. Rare-earth doped LaF3 hollow hexagonal nanoplates: hydrothermal synthesis and photoluminescence properties. CrystEngComm 2014, 16, 7106-7114. [CrossRef]

57. Zhou, Z.; Zhao, Z.; Zhang, H.; Wang, Z.; Chen, X.; Wang, R.; Chen, Z.; Gao, J. Interplay between Longitudinal and Transverse Contrasts in $\mathrm{Fe}_{3} \mathrm{O}_{4}$ Nanoplates with (111) Exposed Surfaces. ACS Nano 2014, 8, 7976-7985. [CrossRef] [PubMed]

58. Palchoudhury, S.; Xu, Y.; Rushdi, A.; Holler, R.A.; Bao, Y. Controlled synthesis of iron oxide nanoplates and nanoflowers. Chem. Commun. 2012, 48, 10499. [CrossRef] [PubMed]

59. Baaziz, W.; Pichon, B.; Grenèche, J.-M.; Begin-Colin, S. Effect of environment medium and the in situ formation of precursor on the composition-shape of iron oxide nanoparticles synthesized by thermal decomposition method. CrystEngComm 2018. [CrossRef]

60. McCammon, C.A.; Liu, L. The effects of pressure and temperature on nonstoichiometric wüstite, FexO: The iron-rich phase boundary. Phys. Chem. Miner. 1984, 10, 106-113. [CrossRef]

(C) 2018 by the authors. Licensee MDPI, Basel, Switzerland. This article is an open access article distributed under the terms and conditions of the Creative Commons Attribution (CC BY) license (http://creativecommons.org/licenses/by/4.0/). 